\title{
Bioactivity Fraction of Methanolic Seed Extract of Barringtonia asiatica L. (Kurz.) (Lecythidaceae) Against Spodoptera litura F. (Lepidoptera: Noctuidae)
}

\author{
Teddy Budiyansyah ${ }^{1}$, Danar Dono $^{1 *}$, Rika Meliansyah ${ }^{1}$, Unang Supratman² \\ ${ }^{1}$ Department of Plant Pests and Diseases, Faculty of Agriculture, Universitas Padjadjaran, Jatinangor, West Java, Indonesia, \\ 45363. \\ ${ }^{2}$ Departement of Chemistry, Faculty of Mathematic and Natural Sciences, Universitas Padjadjaran, Jatinangor, West Java \\ Indonesia, 45363.
}

*Corresponding Author: danar.dono@unpad.ac.id

\begin{abstract}
Water seed extract of Barringtonia asiatica was used as fish poison by traditional community. This study aims to determine the bioactivity of methanolic seed extract fraction of B. asiatica against $S$. litura. The extract tested was spread evenly on the leaf surface by using microsyringe. The experiment consisted of 12 treatments and 3 replications. Treatments were concentration of $0.3 \%$ and $0.1 \%$ of fraction $16,17,18,19,20$ of methanolic seed extract of B. asiatica, and concentration of $0.264 \%$ methanolic seed extract of B. asiatica; and control. The results showed that the fraction 19 (20\% EtOAc and $80 \%$ $\mathrm{MeOH}$ eluent) of methanol extract of $B$. asiatica seed has the highest bioactivity against the larvae of $S$. litura. The fraction 19 of methanolic seed extract of $B$. asiatica had $\mathrm{LC}_{50}$ value of $0.182 \%$ at 12 days after treatment. In addition, the 19 fraction of methanolic seed extract of $B$. asiatica decreased food intake, weight and lengthened development time of larvae.
\end{abstract}

Keywords : Barringtonia asiatica, bioactivity, fraction, Spodoptera litura.

\section{ABSTRAK}

Bioaktivitas Fraksi Ekstrak Metanol Biji Barringtonia asiatica L. (Kurz.) (Lecythidaceae) Terhadap Spodoptera litura F. Lepidoptera: Noctuidae)

Ekstak air biji Barringtonia asiatica diketahui biasa digunakan masyarakat tradisional sebagai racun ikan. Namun toksisitasnya terhadap serangga hama tanaman pertanian belum banyak dipelajari. Penelitian bertujuan untuk mengetahui toksisitas fraksi ekstrak metanol biji $B$. asiatica terhadap $S$. litura. Aplikasi ekstrak tumbuhan dilakukan menggunakan metode perlakuan daun pakan. Perlakuan tersebut adalah ekstrak metanol biji B. asiatica Fraksi 16, 17, 18, 19 dan 20 masing masing dengan konsentrasi $0,3 \%$ dan $0,1 \%$; ekstrak metanol biji B. asiatica dengan konsentrasi 0,264\%; serta kontrol. Fraksi yang memiliki toksisitas tertinggi terhadap serangga uji selanjutnya diuji lebih lanjut untuk mengetahui bioaktivitasnya terhadap Spodoptera litura. Hasil penelitian menunjukkan bahwa fraksi 19 ekstrak metanol biji B. asiatica dengan eluent $20 \%$ EtOAc dan $80 \% \mathrm{MeOH}$ memiliki aktivitas insektisida tertinggi terhadap larva S. litura dengan nilai LC $\mathrm{C}_{50}$ sebesar $0,182 \%$ pada 12 hari setelah aplikasi. Selain itu, fraksi 19 ekstrak metanol biji B. asiatica menurunkan konsumsi pakan dan bobot larva uji.

Kata kunci : Barringtonia asiatica, bioaktivitas, fraksi, Spodoptera litura.

\section{PENDAHULUAN}

Penggunaan insektisida yang tidak bijaksana untuk pengendalian hama tanaman dapat mengakibatkan berbagai dampak negatif, beberapa diantaranya yaitu dapat menimbulkan resistensi dan resurgensi hama serta munculnya hama sekunder. Oleh karena itu diperlukan suatu insektisida alternatif yang relatif aman bagi lingkungan dan tentunya efektif terhadap hama sasaran. Barringtonia asiatica L. (KURZ.) merupakan salah satu tumbuhan yang berpotensi untuk dikembangkan sebagai sumber insektisida nabati (Ratnasari et al., 2017). Senyawa yang terkandung dalam $B$. asiatica diantaranya adalah saponin, asam bartogenic, 19epibartogenik, asam anhidrobartogenik, asam hidrosianik, asam galat, dan monosakarida (WHO, 2009).

Burton et al. (2003) melaporkan fraksi butanol biji $B$. asiatica bersifat toksik terhadap udang air tawar (brine-shrimp) pada konsentrasi $20 \mu \mathrm{g} / \mathrm{ml}$.
Ekstrak metanol biji B. asiatica efektif terhadap larva ulat krop kubis, Crocidolomia pavonana, dengan $\mathrm{LC}_{50}$ 0,15\% (Dono \& Sujana, 2007). Ekstrak metanol $B$. asiatica bersifat toksik terhadap $S$. litura dengan nilai $\mathrm{LC}_{50}$ sebesar 0,256\% (Dwijakartika, 2011).

Dalam usaha pencarian senyawa tumbuhan sebagai bahan insektisida diperlukan pemurnian senyawa bioaktif melalui serangkaian proses fraksinasi dan karakterisasi senyawa. Untuk mengetahui senyawa aktif dari metabolit tumbuhan, fraksinasi sebaiknya dipandu dengan uji hayati menggunakan serangga uji. Hal tersebut berkaitan dengan manfaat studi fitokimia tumbuhan untuk pengendalian serangga hama di lapangan dalam rangka pengembangan senyawa aktif asal tumbuhan sebagai insektisida baru (Dadang \& Nugroho, 1999). Oleh karena itu perlu dilakukan penelitian mengenai bioaktivitas fraksi ekstrak metanol biji $B$. asiatica terhadap S. litura. 


\section{BAHAN DAN METODE}

Lima fraksi ekstrak metanol Barringtonia asiatica yang diperoleh proses kromatografi kolom menggunakan perbandingan bergradien sistem pelarut etil asetat : metanol yaitu 50\% EtOAc : $50 \% \mathrm{MeOH}$, 40\% EtOAc : $60 \% \mathrm{MeOH}, 30 \%$ EtOAc : $70 \% \mathrm{MeOH}$, 20\% EtOAc : $80 \% \mathrm{MeOH}$, dan 10\% EtOAc : $90 \%$ $\mathrm{MeOH}$. Fraksi-fraksi tersebut diperoleh dari Laboratorium Kimia Organik, Jurusan Kimia, Fakultas MIPA, Universitas Padjadjaran.

Penelitian dilakukan dalam dua tahap yaitu: tahap pertama proses screening toksisitas fraksi ekstrak metanol biji $B$. asiatica untuk menentukan salah satu fraksi yang memiliki tingkat toksisitas yang paling tinggi dan tahap kedua adalah penentuan nilai toksisitas dari fraksi yang paling toksik tersebut melalui analisis nilai Lethal concentration (LC) dari fraksi tersebut.

\section{Screening toksisitas fraksi ekstrak metanol biji $B$. asiatica}

Tahap pertama yaitu proses screening toksisitas fraksi ekstrak metanol biji B. asiatica untuk menentukan salah satu fraksi yang memiliki tingkat toksisitas yang paling tinggi. Percobaan terdiri dari 12 perlakuan dengan 3 ulangan. Jenis perlakuan dan konsentrasi yang diuji untuk screening tersebut adalah sebagai berikut (Tabel 1):

Tabel 1. Jenis perlakuan screening fraksi ekstrak metanol biji B. asiatica terhadap S. litura instar-1

\begin{tabular}{cccc}
\hline Perlakuan ekstrak/fraksi & eluent & \multicolumn{2}{c}{ Konsentrasi (\%) } \\
\hline Fraksi 16 & $50 \%$ EtOAc : $50 \% \mathrm{MeOH}$ & 0,1 & 0,3 \\
Fraksi 17 & $40 \%$ EtOAc : 60\% MeOH & 0,1 & 0,3 \\
Fraksi 18 & $30 \%$ EtOAc : 70\% MeOH & 0,1 & 0,3 \\
Fraksi 19 & $20 \%$ EtOAc : $80 \% \mathrm{MeOH}$ & 0,1 & 0,3 \\
Fraksi 20 & $10 \%$ EtOAc : $90 \% \mathrm{MeOH}$ & 0,1 & 0,3 \\
Ekstrak metanol & - & 0,264 & - \\
kontrol & - & 0 & - \\
\hline
\end{tabular}

Keterangan: $\mathrm{EtOAc}=$ etil asetat, $\mathrm{MeOH}=$ metanol

Fraksi yang mengakibatkan kematian serangga uji paling tinggi selanjutnya diuji lebih lanjut pada uji tahap kedua untuk menentukan nilai toksisitasnya melalui uji pendahuluan dan uji lanjutan.

\section{Uji Toksisitas Fraksi Aktif Hasil Screening}

Pengujian ini dilakukan untuk menentukan hubungan konsentrasi yang dapat menyebabkan mortalitas S. litura sebesar 10\% - 90\%. Konsentrasi yang digunakan yaitu lima taraf konsentrasi yang ditentukan berdasarkan deret geometri. Percobaan terdiri dari enam perlakuan dengan tiga ulangan yang setiap unit perlakuan menggunakan 10 ekor serangga uji instar I larva $S$. litura. Hubungan Konsentrasi ekstrak dengan data mortalitas serangga uji yang diperoleh dianalisis probit menggunakan program POLO - PC Leora soft ware.

\section{Pelaksanaan Percobaan}

Perlakuan fraksi dan ekstrak menggunakan metode pengolesan daun pakan menggunakan microsyringe. Fraksi dan ekstrak biji $B$. asiatica dilarutkan dalam metanol. Daun pakan yang digunakan yaitu daun talas berukuran 4 x $4 \mathrm{~cm}$ diolesi masing-masing fraksi ekstrak metanol biji $B$. asiatica dengan konsentrasi sesuai perlakuan dengan menggunakan microsyringe dengan dosis $100 \mu \mathrm{l}$ per sisi daun pakan. Selanjutnya potongan daun yang telah diberi perlakuan tersebut dikeringanginkan. Daun talas yang telah diberi perlakuan sebanyak satu buah dimasukan ke dalam wadah plastik berukuran 10 $\mathrm{x} 9$ x 4,5 cm yang telah dilapisi kertas tisu. Kemudian, S. litura instar I dimasukan ke dalam stoples tersebut sebanyak 10 ekor. Pemberian daun pakan berperlakuan dilakukan selama dua hari. Pada tiga hari setelah perlakuan hingga seterusnya daun pakan diganti dengan daun pakan tanpa perlakuan. Mortalitas larva uji diamati hingga larva memasuki instar IV.

\section{HASIL DAN PEMBAHASAN}

\section{Screening Toksisitas Fraksi Ekstrak Metanol Biji Barringtonia asiatica terhadap Mortalitas Larva Spodoptera litura}

Hasil pengujian diperoleh fraksi yang menunjukkan nilai mortalitas lebih dari $50 \%$ yaitu secara berurutan adalah fraksi 19 dan fraksi 17. Namun fraksi lainnya juga mengakibatkan kematian serangga uji dengan kisaran mortalitas antara $16 \%$ hingga $23 \%$ (Tabel 2).

Proses fraksinasi dengan kombinasi dua jenis eluent yang kadarnya bergradasi yaitu methanol dan etil asetat menunjukkan hasil pengujian dengan nilai mortalitas serangga uji yang bervariasi untuk setiap fraksi yang dihasilkan. Dari kelima fraksi yang diperoleh dapat dilihat bahwa, fraksi 19 merupakan fraksi yang memberikan efek mortalitas tertinggi. Hal ini menunjukkan bahwa fraksi 19 ekstrak biji $B$. asiatica memiliki kandungan atau aktivitas senyawa bioaktif tertinggi. Fraksi 19 menggunakan eluent berupa $20 \%$ etil asetat dan $80 \%$ metanol berdasarkan metode stepwise kromatografi vakum cair (KVC).

Peningkatan mortalitas larva sejalan dengan peningkatan konsentrasi yang diberikan, dimana pada 12 hari setelah aplikasi, mortalitas larva dengan perlakuan fraksi 19 konsentrasi $1,5 \%$ adalah sebesar $83,33 \%$, sedangkan konsentrasi $0,01 \%$ sebesar $20 \%$. 
Pada perlakuan konsentrasi 0,45\%; 0,13\% dan 0,04\% menunjukkan tidak berbeda nyatanya nilai mortalitas.

Larva $S$. litura yang mati akan menunjukkan gejala mengering dengan ukuran yang lebih kecil dari perlakuan kontrol (Gambar 1). Hal tersebut diduga menunjukkan kandungan senyawa dari fraksi 19 ekstrak metanol biji $B$. asiatica dapat mengganggu sistem kerja metabolisme tubuh larva terutama sistem pencernaan. Hal tersebut sesuai dengan hasil penelitian Maharani et al. (2009) yang menyebutkan kandungan utama dari $B$. asiatica adalah saponin.

Insektisida akan masuk ke organ pencernaan serangga dan diserap oleh dinding usus kemudian ditranslokasikan ke tempat sasaran. Terganggunya proses pergantian kulit akibat pemberian fraksi 19 ekstrak metanol biji $B$. asiatica diduga karena kandungan saponin dalam fraksi tersebut. Terdapatnya senyawa saponin akan mengikat sterol pada saluran pencernaan makanan sehingga akan menurunkan sterol dalam hemolimfa (Gerhenzon \& Croteu, 1991). Satu peran penting sterol bagi serangga adalah sebagai prekursor dari hormon ekdison yang merupakan hormone untuk molting, mengganggu snyal hedgehog (Behmer \& Nes, 2003). Sehingga, jika sterol terganggu maka akan terjadi gangguan juga pada proses pertumbuhan dan perkembangan serangga.

Tabel 2. Rata-rata Mortalitas larva S. litura pada 12 hari setelah aplikasi uji screening toksisitas fraksi ekstrak metanol biji B. asiatica .

\begin{tabular}{|c|c|c|c|}
\hline Perlakuan & eluent & Konsentrasi (\%) & $\%$ Mortalitas \pm SB \\
\hline \multirow{2}{*}{ F 16} & $50 \%$ EtOAc : $50 \% \mathrm{MeOH}$ & 0,3 & $23,33 \pm 5,77$ \\
\hline & & 0,1 & $16,67 \pm 5,77$ \\
\hline \multirow{2}{*}{ F 17} & $40 \%$ EtOAc : $60 \% \mathrm{MeOH}$ & 0,3 & $53,33 \pm 11,54$ \\
\hline & & 0,1 & $53,33 \pm 20,81$ \\
\hline \multirow{2}{*}{ F 18} & $30 \%$ EtOAc : $70 \% \mathrm{MeOH}$ & 0,3 & $40,00 \pm 10,00$ \\
\hline & & 0,1 & $36,67 \pm 20,81$ \\
\hline \multirow{2}{*}{ F 19} & $20 \%$ EtOAc : $80 \% \mathrm{MeOH}$ & 0,3 & $60,00 \pm 10,00$ \\
\hline & & 0,1 & $30,00 \pm 26,45$ \\
\hline \multirow{2}{*}{ F 20} & $10 \%$ EtOAc : $90 \% \mathrm{MeOH}$ & 0,3 & $26,67 \pm 11,54$ \\
\hline & & 0,1 & $16,67 \pm 15,27$ \\
\hline ekstrak metanol & - & 0,264 & $23,33 \pm 15,27$ \\
\hline kontrol & - & 0 & $16,67 \pm 5,77$ \\
\hline
\end{tabular}

SB : simpangan baku

Toksisitas Fraksi Aktif terhadap larva $S$. litura

Hasil pengujian pengaruh fraksi 19 ekstrak metanol biji B. asiatica pada semua taraf konsentrasi yang diuji menunjukkan efek toksik terhadap larva $S$. litura. Dari semua taraf konsentrasi yang diuji, efek mortalitas tertinggi ditunjukan oleh konsentrasi 1,5\%, sedangkan konsentrasi $0,01 \%$ menunjukkan hasil yang paling rendah. Kematian larva pada konsentrasi $1,5 \%$ terjadi sejak hari pertama setelah aplikasi hingga hari ke 12. Nilai mortalitas tertinggi terjadi pada tiga hari pertama dimana larva $S$. litura mengonsumsi pakan yang mengandung fraksi ekstrak metanol biji $B$. asiatica sesuai dengan konsentrasi yang diberikan. Sedangkan pada hari ke empat dan seterusnya, peningkatan mortalitas berjalan dengan lambat. Senyawa saponin mengakibatkan kematian sel dan sehingga kematian serangga secara tidak langsung atau secara lambat laun (Syahroni \& Prijono, 2013).

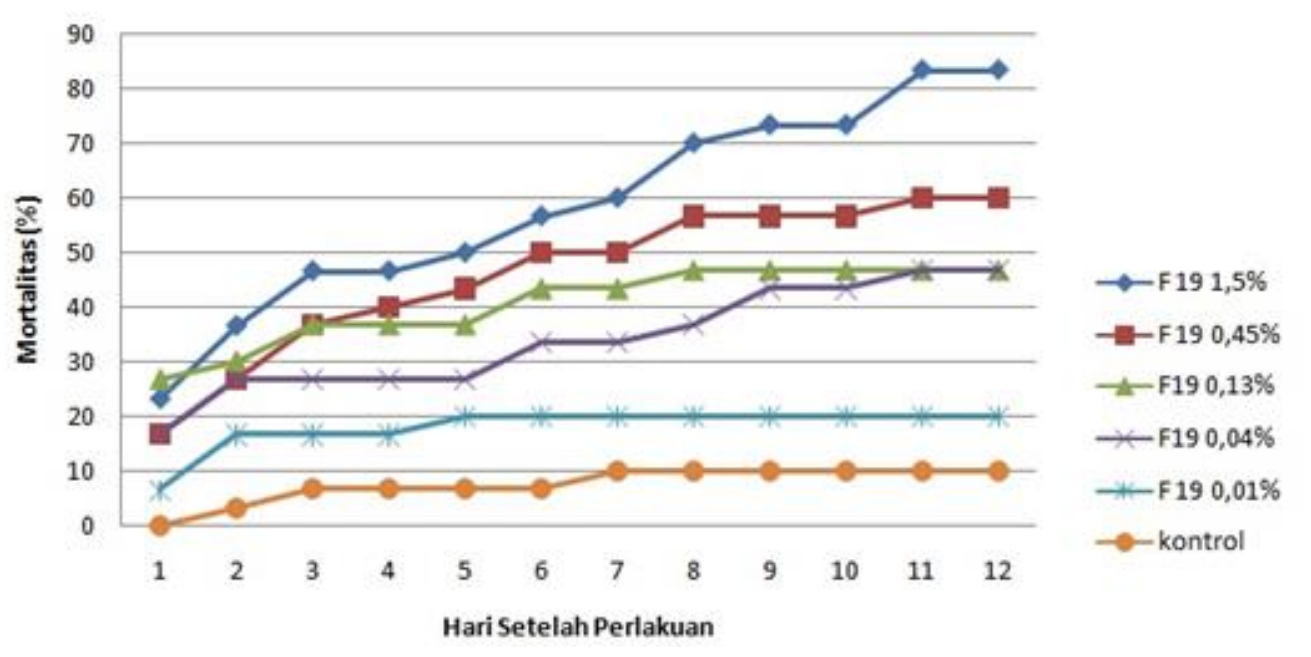

Grafik 1. Mortalitas larva S. litura pada uji fraksi 19 (eluent 20\% EtOAc : 80\% MeOH) ekstrak metanol 
biji B. asiatica .

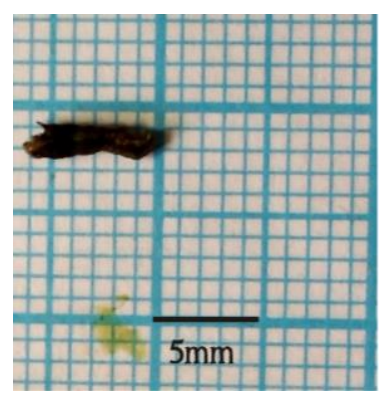

(A)



(B)

Gambar 1. Larva S. litura pada perlakuan fraksi 19 ekstrak metanol biji B. asiatica tujuh hari setelah perlakuan (A) larva S. litura yang mati pada perlakuan dengan konsentrasi $1,5 \%$, (B) larva $S$. litura yang hidup pada perlakuan kontrol.

Analisis probit menunjukkan penurunan nilai $\mathrm{LC}_{50}$ sejak hari pertama hingga hari ke 12 . Nilai $\mathrm{LC}_{50}$ pada hari kedua menunjukkan nilai 79,904\% dimana tingginya nilai $\mathrm{LC}_{50}$ tersebut menunjukkan bahwa data yang didapatkan belumlah stabil (Tabel 3). Pada 4 HSA menunjukkan nilai $\mathrm{LC}_{50} \quad 2,846 \%$ yang menunjukkan penurunan nila $\mathrm{LC}_{50}$ yang cukup tinggi. Pada 6 HSA hingga $10 \mathrm{HSA}$, nilai $\mathrm{LC}_{50}$ berkisar antara $0,273 \%$ - 0,892 dan pada 12 HSA nilai LC $_{50}$ sebesar $0,182 \%$. Pada 6 HSA hingga 12 HSA, nilai $\mathrm{LC}_{50}$ berangsung-angsur mengalami penurunan seiring dengan peningkatan nilai mortalitas larva. Hal tersebut menunjukkan bahwa efek penghambatan makan terhadap larva $S$. litura yang telah mengonsumsi pakan yang telah dilapisi oleh fraksi 19 ekstrak metanol $B$. asiatica mengakibatkan kematian yang cukup lama dari populasi serangga uji.

Berdasarkan hasil analisis $\mathrm{LC}_{50}$ (Tabel 3), ekstrak metanol biji B. asiatica bersifat toksik terhadap larva $S$. litura. Diduga kematian ini diakibatkan senyawa antifidan yang didefinisikan sebagai suatu zat yang apabila diujikan terhadap serangga akan menghentikan aktivitas makan secara sementara atau permanen tergantung potensi zat tersebut. Dari pernyataan tersebut maka antifidan dapat berupa penolakan makan dengan tidak ada aktivitas makan sama sekali. Dalam hal ini ekstrak metanol biji $B$. asiatica memberikan efek hambatan terhadap oviposisi, menurunkan konsumsi larva, dan perkembangan larva (Dono, 2008).

\section{Pengaruh Fraksi terhadap Konsumsi pakan larva S. litura}

Fraksi 19 ekstrak metanol biji B. asiatica mengakibatkan penurunan pakan yang dikonsumsi larva uji. Semakin tinggi konsentrasi yang diuji maka semakin rendah pakan yang dikonsumsi. Hal tersebut kemungkinan disebabkan pada perlakuan dengan konsentrasi tinggi, terjadi proses penghambatan makan pada sistem pencernaan serangga tersebut (Gambar 2).
Nilai konsumsi pakan pada konsentasi 1,5\% hari pertama, kedua dan ketiga secara berurut adalah sebesar 7,33\%, 12,67\% dan 18\%. Kenaikan nilai konsumsi tersebut meningkat seiring dengan usia larva, dengan presentase rata-rata angka konsumsi pakan sebesar $57,45 \%$. Sedangkan pada perlakuan kontrol, konsumsi pakan pada hari pertama, kedua dan ketiga secara berurut adalah sebesar 10,33\%, $23,33 \%$ dan $33 \%$ dengan presentase rata-rata angka konsumsi pakan sebesar $83,64 \%$. Perbedaan nilai konsumsi pakan tersebut diduga menunjukkan adanya penghambatan makan yang disebabkan oleh perlakuan fraksi 19 ekstrak B. asiatica. Proses penghambatan makan tersebut sejalan dengan pernyataan Ambarningrum et al. (2009) bahwa senyawa toksik yang terkandung dalam pakan akan memengaruhi nilai konsumsi yang lebih biasa disebut dengan efek penghambatan makan.

Berdasarkan waktu pengamatan, pada satu hari setelah aplikasi nilai konsumsi pakan semua perlakuan fraksi tidak menunjukkan nilai berbeda nyata. Hal tersebut menunjukkan bahwa pada hari pertama setelah perlakuan tingkat konsumsi pakan larva S. litura belum tinggi. Pada pengamatan dua dan tiga hari setelah aplikasi nilai konsumsi pakan menunjukkan nilai yang beragam dan berurutan sesuai dengan nilai konsentrasi yang diberikan. Semakin tinggi nilai konsentrasi akan menunjukkan nilai konsumsi pakan yang semakin kecil. Hal tersebut menunjukkan adanya efek penghambatan makan atau antifidan yang disebabkan oleh perlakuan fraksi 19 ekstrak metanol biji B. asiatica .

\section{Pengaruh Fraksi terhadap Bobot dan panjang Larva $S$. litura}

Fraksi 19 ekstrak metanol biji B. asiatica menunjukkan pengaruh terhadap bobot dan panjang larva S. litura. Larva dengan perlakuan fraksi 19 berbagai konsentrasi memiliki bobot dan panjang larva yang lebih kecil dari pada perlakuan kontrol. Berdasarkan data (Tabel 5), nilai penurunan berat 
rata-rata larva yang menunjukkan semakin tinggi konsentrasi akan semakin rendah nilai berat rata rata larva tersebut. Hal tersebut berkorelasi positif dengan pengamatan sebelumnya mengenai nilai konsumsi pakan. Semakin kecil konsumsi larva, maka juga akan memengaruhi pertumbuhan dan perkembangan tubuh larva tersebut. Hal tersebut akan mengakibatkan berat rata rata larva akan lebih kecil dibandingkan dengan perlakuan kontrol.
Semakin tinggi tingkat konsumsi pakan, maka akan semakin besar bobot dan panjang larva. Hal ini disebabkan semakin banyak makanan yang dikonsumsi maka semakin banyak energi yang diperoleh untuk pertumbuhan. Kemampuan serangga untuk mengkonsumsi pakan akan menurun dan terjadi gangguan fisiologis akibat senyawa bioaktif dari fraksi 19 ekstrak metanol biji $B$. asiatica sehingga berdampak pada menurunnya bobot larva dan ukuran larva.

Tabel Regresi probit hubungan konsentrasi fraksi 19 ekstrak metanol biji B.asiatica dengan mortalitas S. litura 3. berdasarkan waktu pengamatan.

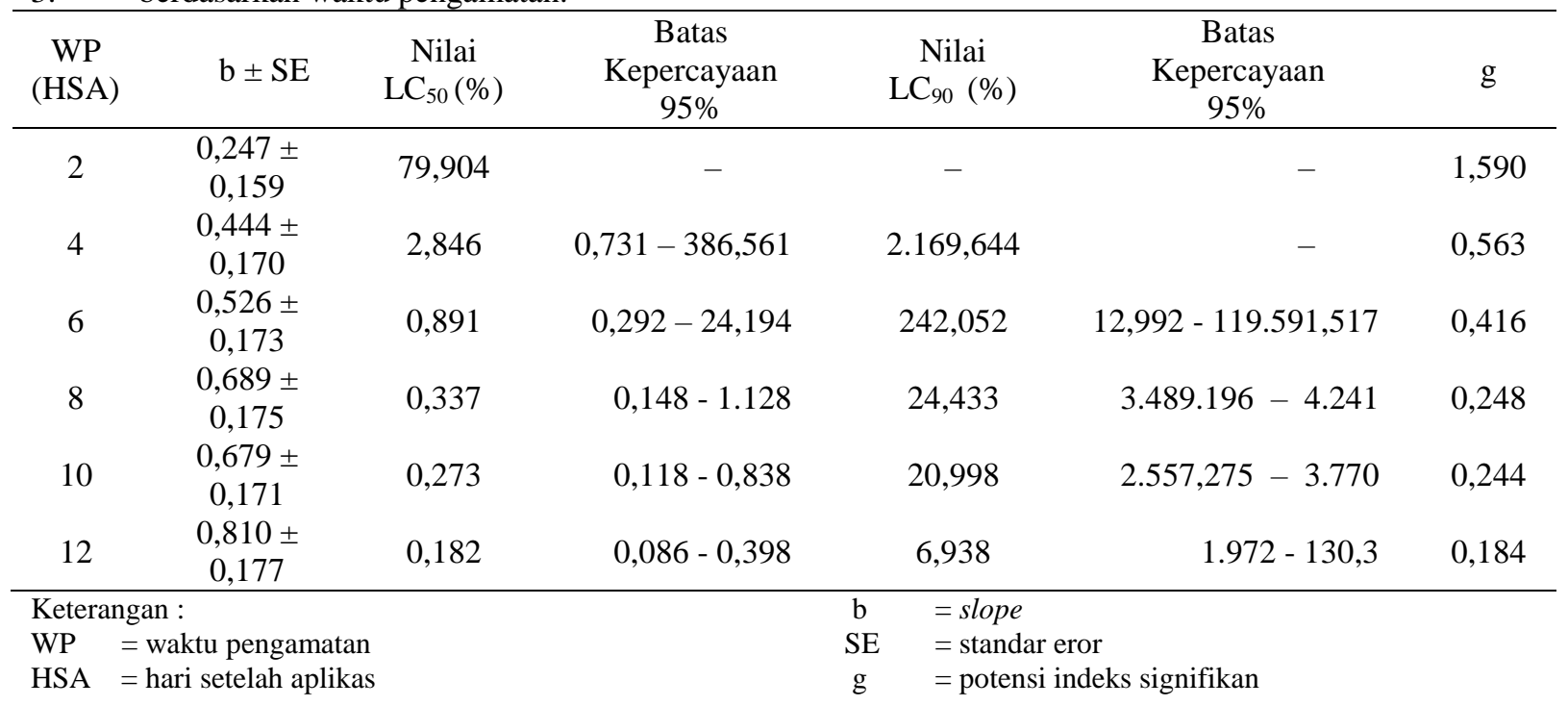

Tabel 4. Rata-rata nilai konsumsi pakan larva S. litura

\begin{tabular}{crll}
\hline \multirow{2}{*}{ Perlakuan } & \multicolumn{3}{c}{ Konsumsi pakan $(\%) \pm$ SB } \\
F19 $1,5 \%$ & $7,33 \pm 4,16 \mathrm{a}$ & $12,67 \pm 9,07 \mathrm{a}$ & \multicolumn{1}{c}{ 3 HSA } \\
F19 0,45\% & $9,67 \pm 5,68 \mathrm{a}$ & $18,00 \pm 8,71 \mathrm{ab}$ & $18,00 \pm 8,18 \mathrm{a}$ \\
F19 0,13\% & $11,00 \pm 8,71 \mathrm{a}$ & $17,33 \pm 12,74 \mathrm{ab}$ & $23,00 \pm 8,71 \mathrm{ab}$ \\
F19 0,04\% & $11,33 \pm 6,80 \mathrm{a}$ & $22,00 \pm 11,78 \mathrm{~b}$ & $27,67 \pm 10,26 \mathrm{bc}$ \\
F19 0,01\% & $9,00 \pm 4,58 \mathrm{a}$ & $25,33 \pm 11,67 \mathrm{bc}$ & $25,00 \pm 11,53 \mathrm{abc}$ \\
kontrol & $21,00 \pm 7,93 \mathrm{~b}$ & $30,33 \pm 3,21 \mathrm{c}$ & $32,00 \pm 8,71 \mathrm{c}$ \\
\hline
\end{tabular}

Keterangan : Angka rata-rata pada tiap kolom yang diikuti huruf yang sama menunjukkan tidak berbeda nyata menurut Uji Jarak Berganda Duncan tarap 5\% SB : nilai simpangan baku

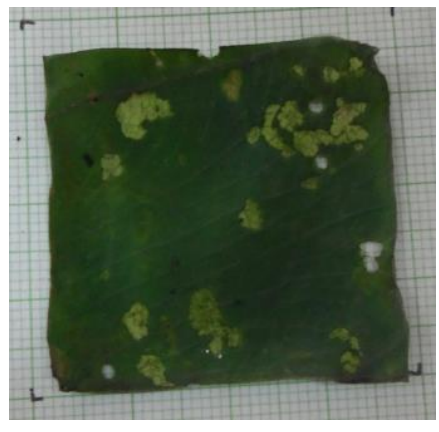

(A)

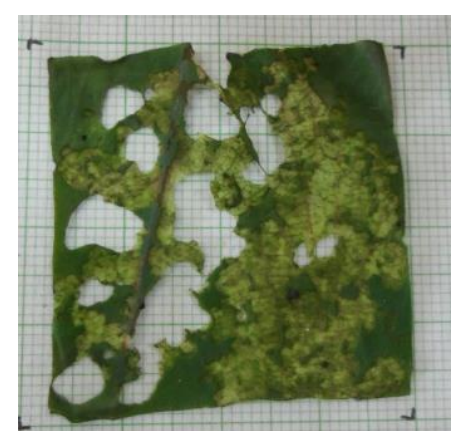

(B)

Gambar 2. Daun pakan yang dikonsumsi larva S. litura tiga hari setelah aplikasi pada perlakuan (A) fraksi 19 ekstrak metanol biji B. asiatica perlakuan dengan konsentrasi 1,5\%; (B) perlakuan kontrol. 
Tabel 5. Rata-rata bobot dan panjang larva S. litura pada 7 HSA dan 12 HSA

\begin{tabular}{ccccc}
\hline \multirow{2}{*}{ Perlakuan } & Pengamatan pada 7 HSA & $\mathrm{N}$ & Pengamatan pada 12 HSA & N \\
\cline { 2 - 4 } & Bobot larva \pm SB $(\mathrm{g})$ & 12 & $0,174 \pm 0,052 \mathrm{a}$ & 5 \\
F19 1,5\% & $0,037 \pm 0,021 \mathrm{a}$ & 15 & $0,485 \pm 0,245 \mathrm{~b}$ & 12 \\
F19 0,45\% & $0,042 \pm 0,032 \mathrm{ab}$ & 17 & $0,570 \pm 0,149 \mathrm{~b}$ & 16 \\
F19 0,13\% & $0,055 \pm 0,037 \mathrm{ab}$ & 20 & $0,555 \pm 0,170 \mathrm{~b}$ & 16 \\
F19 0,04\% & $0,060 \pm 0,033 \mathrm{~b}$ & 24 & $0,537 \pm 0,114 \mathrm{~b}$ & 24 \\
F19 0,01\% & $0,056 \pm 0,023 \mathrm{ab}$ & 27 & $0,645 \pm 0,134 \mathrm{~b}$ & 27 \\
kontrol & $0,062 \pm 0,027 \mathrm{~b}$ & & & $27,593 \pm 1,398 \mathrm{c}$ \\
\hline
\end{tabular}

Keterangan : Angka rata-rata pada tiap kolom yang diikuti huruf yang sama menunjukkan tidak berbeda nyata menurut Uji Jarak Berganda Duncan tarap 5\%

SB : simpangan baku

\section{KESIMPULAN}

Berdasarkan hasil penelitian dapat disimpulkan bahwa fraksi 19 ekstrak metanol biji Barringtonia asiatica memiliki bioaktivitas tinggi terhadap larva Spodoptera litura. Fraksi 19 ekstrak metanol biji $B$. asiatica dengan eluent $20 \%$ EtOAc dan $80 \% \mathrm{MeOH}$ memberikan efek mortalitas dengan nilai $\mathrm{LC}_{50}$ sebesar $0,182 \%$ pada 12 hari setelah aplikasi. Selain itu, fraksi 19 ekstrak metanol biji B. asiatica menurunkan konsumsi pakan dan bobot larva uji.

\section{DAFTAR PUSTAKA}

Ambarningrum, T. B.; H. Pratikyo dan S. Priyanto. 2009. Indeks Nutrisi dan Kesintasan Larva Spodoptera litura F. yang Diberikan Pakan Mengandung Ekstrak Kulit Jengkol (Pithellobium lobatum Benth.) Jurnal HPT Tropika. Volume 9, No. 2: 109 - 114. Tahun 2009.

Behmer, ST., \& WD Nes. 2003. Insect Sterol Nutrition and Physiology: A Global Overview. Advances In Insect Physiology Vol. 31. Doi: 10.1016/S0065-2806(03)31001-X

Burton, R. A.; S. G. Wood \& N. L. Owen. 2003. Elucidation of a New Oleanane Glycoside from Barringtonia asiatica. ARKIVOC 2003 (xiii) 137-146. Department of Chemistry and Biochemistry, Brigham Young University, Provo. Utah 84602

Dadang dan B. W. Nugroho. 1999. Bahan Pelatihan Pengembangan dan Pemanfaatan Insektisida Alami. Pusat Kajian Pengendalian Hama Terpadu Institut Pertanian Bogor.

Dono, D. 2008. Bioactivity methanolic seed eztract of Barringtonia asiatica (Lecythidaceae) against Crocidolomia pavonana (Lepidptera: Pyralidae). Proceeding of the International seminar of Chemistry. 30-31 October 2008. Halamn 589-594.

Dono, D. dan N. Sujana. 2007. Aktivitas Insektisidal Ekstrak Barringtonia asiatica (L.) KURZ. (Lecythidaceae) Terhadap Larva Crocidolomia pavonana F. (Lepidoptera: Pyralidae) dan
Fitotoksisitasnya pada tanaman Talas. J. Agrikultura, 18 (1): 5-14.

Dwijakartika, R. R. 2011. Toksisitas Ekstrak Metanol Biji Bitung (Barringtonia asiatica L. (KURZ.)) dan Delapan Genotip Biji Bengkuang (Pachyrhizus spp.) serta Campurannya terhadap Spodoptera litura F.

Gershenzon, J. \& R. Croteu. 1991 Terpenoid .Pages 165-209. In G.A. Rosental \& M.R Barenbaun. Eds Herbivores their interaction with secondary plant metabolites. $2^{\text {nd }}$ edition academic press. New York.

Maharani, R. S. Ishmayana, Y Hidayat, D, Dono. 2009. An Insecticidal compound from Barringtonia asiatica. Sains dan Terapan Kimia. 2(1):48-56.

Retnasari, E. LT Puspasari, R. Meliansayah, R Maharani, Y Hidayat, D Dono. Toxicity of Barringtonia asiatica L. (KURZ.), Melia azedarach L. and Annona muricata L. Seed Extract Mixture Against Larvae Crocidolomia pavonana F. (Lepidoptera:Pyralidae). ICSAFS Conference Proceedings 2nd International Conference on Sustainable Agriculture and Food Security: A Comprehensive Approach, $\mathrm{KnE}$ Life Sciences, pages 246-255. DOI 10.18502/kls.v2i6.1046.

Syahroni, YY. \& D Prijono. 2013. Aktivitas insektisida ekstrak buah Piper aduncum L. (Piperaceae) dan Sapindus rarak DC. (Sapindaceae) serta campurannya terhadap larva Crocidolomia pavonana (F.) (Lepidoptera: Crambidae). Jurnal Entomologi Indonesia. $10 \quad(1): 39-50 . \quad$ DOI: 10.5994/jei.10.1.39.

WHO. 2009. Medicinalis Plant in papua New Guinea. WHO Library Cataloguing in Publication Data. WHO Western Pacipic Region.

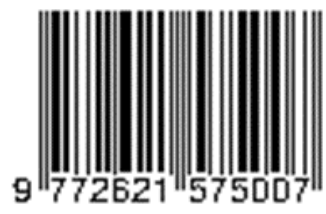

